\title{
Analysis of serum lactate level in septic shock at Emergency Department of Patan Hospital, Nepal
}

\section{Batajoo $\mathrm{KH}^{1}$, Thapa $\mathrm{R}^{2}$, Shrestha $\mathrm{R}^{3}$, Shrestha $\mathrm{A}^{4}$, Acharya $\mathrm{S}^{5}$, Bajracharya $\mathrm{S}^{6}$}

${ }^{1}$ Kabita Hada Batajoo, Associate Professor, KIST Medical College Teaching Hospital, Imadol, Lalitpur; ${ }^{2}$ Rashmi Thapa, Senior Consultant, Kathmandu Medical College, Kathmandu; ${ }^{3}$ Roshana Shrestha, Associate Professor, Manmohan Memorial Teaching Hospital; ${ }^{4}$ Ashis Shrestha, Lecturer; ${ }^{5}$ Samita Acharya, Assistant Professor; ${ }^{6}$ Sumana Bajracharya, Lecturer, Patan Academy of Health Sciences, Lalitpur, Nepal

\begin{abstract}
Background: Sepsis is a leading cause of death in emergency department. Serum lactate level assessment can play an important role for risk assessment and prognostication in critically ill septic patient.

Objective: The objective of this study is to determine the relevance of initial serum lactate measurement after the implementation of sepsis protocol in emergency department, based on guidelines of Surviving Sepsis Campaign.

Methods: This was a cross sectional descriptive study conducted at Patan Hospital from January 2014 to January 2015 among 94 sample of serum lactate who had clinical suspicion of sepsis as per established sepsis emergency department protocol. Data of serum lactate sent from emergency department was noted from the registry book of department of biochemistry, Patan Academy of Health Sciences. Based on clinical practice the obtained lactate results were stratified intothreerisk groups: high ( $>4 \mathrm{mmol} / \mathrm{L}$ ), intermediate ( 2.5 to $3.99 \mathrm{mmol} / \mathrm{L}$ ) and low (<2.5 $\mathrm{mmol} / \mathrm{L})$.

Result: Out of the total 94 samples, 56 (59.6\%) were male and 38 (40.4\%) were female. Mean lactate level in males was $5.73 \mathrm{mmol} / \mathrm{L}$ and that in females was $5.47 \mathrm{mmol} / \mathrm{L}$. Abnormal lactate level was predominantly high 85 (80\%) out of which 31 (29\%) had intermediate whereas more than half 54 (50.76\%) had high lactate level.

Conclusion: This study tells that clinically diagnosed sepsis do have higher serum lactate level. So, in our context, this needs to be explored to be used for early diagnosis of sepsis.
\end{abstract}

Key words: Emergency, Sepsis, Serum Lactate Level

\section{INTRODUCTION}

epsis is a challenge in Emergency department (ED) for its significant morbidity and mortality rate between $30 \%$ and $50 \%{ }^{1,2}$. Early detection of sepsis is complex due to subtle clinical picture. There are numbers of tests and biomarkers like $\mathrm{C}$-reactive protein and prolactin for risk stratification of sepsis. However, no single test is reliable as sepsis increases inflammatory reaction ${ }^{2}$. Along with clinical assessment, serum lactate is useful tool for prognostic prediction of critically ill patient. It is an indicator of cellular hypoxia which leads to anaerobic tissue metabolism that increases lactate production and decreases lactate clearance ${ }^{3,4}$. There are numerous international studies done on prognostic

Address for correspondence

Dr. Kabita Hada Batajoo

Associate Professor

Department of Family Medicine and Emergency Medicine

Kist Medical College Teaching Hospital, Imadol, Nepal

E-mail:kabu_raj@yahoo.com value of lactate, however limited studies have been done in Nepal ${ }^{1,2,5,6}$. A protocol-based approach showed more cases of sepsis detection and sepsis was found to be the most common cause of mortality at Patan hospital ${ }^{7}$. The objective of this study was to see the level of lactate in patients who are clinically diagnosed as a case of septic shock in emergency department.

\section{METHOD}

This was a retrospective cross sectional descriptive study conducted at Patan Hospital from January 2014 to January 2015. All records of lactate measurement done during this period were included in the study. In those patients, lactate was sent as a part of sepsis protocol from the patient ${ }^{7}$. Patients more than 18 years as per record were included in the study and those not meeting inclusion criteria, incomplete records and lactate sent from other department were excluded from the study. Lactate was measured from standard biochemistry analyzer at Patan Hospital. Data collection 
was done from the registry book from the Department of Biochemistry, Patan Academy of Health Sciences (PAHS). Based on clinical practice, the obtained lactate results were stratified into three risk groups: high ( $>4$ $\mathrm{mmol} / \mathrm{L}$ ), intermediate ( 2.5 to $3.99 \mathrm{mmol} / \mathrm{L}$ ) and low (< $2.5 \mathrm{mmol} / \mathrm{L})^{1,3,9,10}$. Data was entered in excel sheet and analysis was done with Statistical Package for Social Sciences version 16. Mean and ratio were calculated and t-test was used to compare the means in sub group analysis. Ethical approval was taken from institutional review board of PAHS.

\section{RESULTS}

The total (94) samples of serum lactate were sent in the period of one year from January 2014 to January 2015 who had clinical suspicion of sepsis as per established sepsis ED protocol. Out of the 94 patients with clinical diagnosis of sepsis, 56 (59.6\%) were male and 38 (40.4\%) were female.

Mean lactate level was $5.6 \mathrm{mmol} / \mathrm{L}(\mathrm{SD} \pm 3.5) ; 5.73$ $\mathrm{mmol} / \mathrm{L}$ among the males and $5.47 \mathrm{mmol} / \mathrm{L}$ among the females $(P=0.1)$. Patients presenting with severe sepsis had abnormal lactate level $80 \%$ (85), out of which $29 \%$ (31) had intermediateand more than half $50.76 \%$ (54) had high lactate level.

Females have more normal and moderate lactate level than males. Likewise in severe stage, males had higher lactate level in comparison to females. The distribution of gender per lactate level was statistically not significant (Table 1).

\section{DISCUSSION}

This study demonstrates that the majority of the patients meeting the criteria of sepsis protocol had abnormal serum lactate (80\%), among which $29 \%$ had intermediate and half of them had high serum lactate. Various clinical trials have been done for early detection and enhancements of early goal directed therapy have proven improvement in the clinical outcome ${ }^{11-13}$. Severe sepsis and septic shock are the leading causes of hospital admission and deaths ${ }^{7}$. A study done by Mark et.al revealed maximum patients to be in intermediate lactate level (45.3\%). Most of the patients (50.76\%) in our study whose lactate was sent as per clinically-diagnosed sepsis had very high lactate level. A study done by Portal et al however had maximum number of patients in low lactate group (49.9\%). This reflects towards the increase accuracy of clinical decision with sepsis protocol in our setup. Serum lactate can be the feasible risk stratification prognostic tool in critically ill patient in ED. It also established that mortality benefit is achieved by goal directed therapy ${ }^{2,3}$. Several studies have shown a linear relation of serum lactate level and poor clinical outcome $2,3,5,10,13$. Nathan et al stated that $28 \%$ mortality in patients with lactate level $\geq 4 \mathrm{mmol} / \mathrm{L}$ within three days of hospital admission. Initial high serum lactate alarms clinician for rapid attention and prompt treatment ${ }^{2}$. So the study hypothesized that serum lactate can be a useful screening tool in critically ill patient in ED for prediction of clinical outcome as well as for initiation of early therapy.

Table 1: Comparison of normal and abnormal lactate level according to gender

\begin{tabular}{|c|c|c|c|c|c|}
\hline \multirow{3}{*}{ Lactate Level } & \multicolumn{4}{|c|}{ Gender } & \multirow{3}{*}{ p value } \\
\hline & \multicolumn{2}{|c|}{ Female } & \multicolumn{2}{|c|}{ Male } & \\
\hline & Frequency & Percent & Frequency & Percent & \\
\hline Normal & 5 & 13.1 & 4 & 7.1 & \\
\hline Abnormal & 33 & 86.9 & 52 & 92.9 & 0.26 \\
\hline Total & 38 & 100 & 56 & 100 & \\
\hline
\end{tabular}

Table 2: Categorization of lactate level according to gender

\begin{tabular}{|c|c|c|c|c|c|}
\hline \multirow{3}{*}{ Category } & \multicolumn{4}{|c|}{ Gender } & \multirow{3}{*}{$p$ value } \\
\hline & \multicolumn{2}{|c|}{ Female } & \multicolumn{2}{|c|}{ Male } & \\
\hline & Frequency & Percent & Frequency & Percent & \\
\hline Low & 5 & 55.6 & 4 & 44.4 & \multirow{4}{*}{0.2} \\
\hline Intermediate & 15 & 48.4 & 16 & 51.6 & \\
\hline High & 18 & 33.3 & 36 & 66.6 & \\
\hline Total & 38 & 100 & 56 & 100 & \\
\hline
\end{tabular}


This is a preliminary study and thus has several important limitations. As this was retrospective study, details about patients' demography, comprehensive clinical picture were not taken into account. Multivariable analysis could not be done as registry did not comprise details about co-morbidities, organ dysfunctions, therapies received, etc. Also, the study had only included the serum lactate tests sent by clinicians of variable levels of expertise, so serum lactate may not have been obtained among those who might have met sepsis protocol. As many studies have considered serum lactate as a predictor of mortality in septic patients, our study has not done critical analysis of serum lactate obtained with its clinical outcome.

\section{CONCLUSION}

This study reveals that high initial serum lactate is seen in patients with severe sepsis and septic shock as per sepsis protocol based on Surviving Sepsis Campaign guidelines which further adds up to confirm sepsis. Further studies possibly with multicenter data are required to get a greater picture.

\section{REFERENCES}

1. Rivers E, Nguyen B, Havstad S, Ressler J, Muzzin A, Knoblich $B$, et al. Early goal-directed therapy in the treatment of severe sepsis and septic shock. N Engl J Med. 2001;345:1368-77.

2. Shapiro NI,Howell MD, Talmor D, Nathanson LA, Lisbon A, Wolfe RE, et al.Serum lactate as a predictor of mortality in emergency department patients with infection. Ann Emerg Med. 2005;45:5248.

3. Trzeciak S, Dellinger RP, Chansky ME, Arnold RC, Schorr C, Milcarek B, et al. Serum lactate as a predictor of mortality in patients with infection. Intensive Care Med. 2007;33:970-77.

4. Jean-Pierre R, Tappy L, Martinez A, Bollmann M, Cayeux MC, Berger M, et al. Lactate and glucose metabolism in severe sepsis and cardiogenic shock. Crit Care Med. 2005;33(10):2235-40.

5. Nguyen HB, Rivers EP, Knoblich BP, Jacobsen G, Muzzin A, Ressler JA, et al. Early lactate clearance is associated with improved outcome in severe sepsis and septic shock. Crit Care Med. 2004;32(8):1637-42.

6. Mikkelsen ME, Gaieski DF, Goyal M, Fuchs BD, Shah $\mathrm{CV}$, Bellamy SL, et al. Serum lactate is associated with mortality in severe sepsis independent of organ failure and shock. Crit Care Med. 2009;37(5):1670-77.
7. Bajracharya S, Shrestha A. Follow up study of mortality after clinicalprotocol based intervention at emergency of Patan hospital. Journal of Patan Academy of Health Sciences. 2014;1(1):13-15.

8. Bruno L, Laure-Odile S, Anne-Marie G, Pierre-Edouard B, Nabet P, Larcan A. Evolution of lactate pyruvate and arterial ketone body ratios in the early course of catecolamine- treated septic shock. Crit Care Med. 2000;28(1):114-9.

9. Smith I, Kumar P, Molloy S, Rhodes A, Newman PJ, Grounds RM, et al. Base excess and lactate as prostic indicators for patients admitted in intensive care. Intensive Care Med. 2001;27:74-83.

10. Dellinger RP, Carlet JM, Masur H, Gerlach H, Calandra T, Cohen J, et al. Surviving Sepsis Campaign guidelines for management of severe sepsis and septic shock. Intensive Care Med. 2004;30:536-55.

11. Howell MD, Donnino M, Clardy P, Talmor D, Shapiro NI. Occult hypoperfusion and mortality in patients with suspected infection. Intensive Care Med. 2007;33:1892-9.

12. Hazel-Ann B, Brunt LK, Mitchem KL, Chaloner C. Does lactate measurement performed on admission predict clinical outcome on intensive care unit? A concise systematic review. Ann Clin Boichem. 2012;49:391-94. 